\title{
LXII. Geometry and geometers
}

\section{T.S. Davies Esq. F.R.S. F.S.A.}

To cite this article: T.S. Davies Esq. F.R.S. F.S.A. (1849) LXII. Geometry and geometers, Philosophical Magazine Series 3, 35:239, 497-510, DOI: 10.1080/14786444908646403

To link to this article: http://dx.doi.org/10.1080/14786444908646403

册 Published online: 30 Apr 2009.

Submit your article to this journal 준

Џll Article views: 2

Q View related articles $₫$ 
to depend, at present, as little as possible on the mechanical violence of the drops of water; because some experiments, not yet fit for publication, seem to show that when steam and air at the same temperature are discharged into the atmosphere, the amount of water simultaneously discharged may be greatly reduced, perhaps to nothing.

69. The negative state of the air, which one would expect to find particularly strong just after a thunder-storm, may slowly discharge itself on the earth by conduction, or on the clouds, or rain, and thus to the earth by convection; nevertheless the direct tendency of lightning, according to this theory, is to render the upper regions negative; and the facilities for the return of this negative charge to the earth will decrease in some proportion as the altitude increases. The continual thunder-storms of the hotter climates may therefore gradually accumulate a powerful negative charge in the heavens. Suppose now, when the air is thus highly charged, that $n$ column of mist sufficiently high and dense to act the part of an electric conductor to the positive earth and negative heavens should be interposed between them, the electricity would then pass as a series of disruptive discharges, and would, I suppose, be the aurora.

7 Prospect Place, Ball's Pond Road, 3rd December 1849.

LXII. Geometry and Geometers. Collected by T. S. Davies, Esq., F.R.S. and F.S.A.*

No. IV.

THE printing of the three letters of John Bernoulli to Cramer, which I had designed to give as the next of this series of "gossipings," must be deferred for awhile; as, from particular considerations, I am led to think it desirable to confine myself, for the present at least, to matters of more purely English interest.

In $1747 \mathrm{Mr}$. Thomas Simpson published the first edition of his Elements of Geometry; and in $1756 \mathrm{Dr}$. Simson the first edition of his Euclid. In this latter work are two notes upon objections which had been raised in the former, to some of Enclid's processes. In $1760 \mathrm{Mr}$. Simpson published the second edition of his Elements, in which he defends himself with great earnestness on those topics; and Dr. Hutton (in his Life of Simpson, prefixed to the Select Exercises, ed. of

* Communicated by the Author.

Phil. Mag. S. 3. No. 239. Suppl. Vol. 35. 
1792) states that these criticisms of Dr. Simson's gave him "some trouble and vexation,"- though on what ground, except his own sensitive nature under prostrated health and its consequent depression of spirits, it would be hard to tell. The man who could maintain his temper under the offensive ribaldry of the notorions Robert Heath, could not on any other supposition than this, feel wounded very deeply by the plain, though, it must be confessed, somewhat contemptuous language of Simson, in those notes. Dr. Hutton further says, that $\mathrm{Dr}$. Simson again replied in the notes to his next edition of Euclid (Life of Simpson, p. xi.). Also Dr. Trail (Life of Simson, p. 31), remarks that "some animadversions were made on this edition (1756) chiefly by those whose works had been criticised in the Doctor's notes; and to some of these, in a second edition, replies and explanations were made." These, of course, Simpson never read, as the edition referred to was not actually published till 1762, whilst Simpson died the year before, and had been some months prior to this in a state that precluded reading and study of every kind. Nor is there in the notes at the end of the second edition of his Geometry anything to induce a belief that he wrote them under any irritable feelings; and we have his distinct averment, at p. 263 (I quote from the fourth edition, which seems to be paged precisely as the previous two), that he was ignorant of the existence of Dr. Simson's Euclid till the middle of November 1759, and his own work is dated March 3 of the following year, when he was in a most enfeebled condition. This was indeed his last connexion with the press, if we except his preparation of the Ladies' Diary for the following year; in which, however, there is reason to believe that he was greatly assisted by his firiend and successor, Edward Rollinson.

I have collated with some care the one hundred and five notes given by Dr. Simson in the first and second editions of his Euclid. There are but few variations in the greater part of them; and even these merely verbal, or of the most casual kind. As regards our present purpose, it is enough to state that in the 8vo edition Simpson is referred to four times, and in the 4to only twice; and that these two notes are alike in both those editions. They are upon $i .22,24$ and 25 , and $x i .1$; the second and fourth of these first appearing in the 8 vo edition.

Dr. Simson, however, wrote a more expanded series of criticisms on Mr. Simpson's notes, a copy of which (in Nourse's hand) is amongst the papers I formerly described. An exact transcript of the original it evidently is; and a memorandum 
at the head identifies its authorship and purpose. The paper itself has much the appearance of being intended for press, though there is not the least reason to think it ever was printed. On this account I give it entire. Probably it was cancelled on account of Simpson's intimacy with Nourse.

"Remarks upon some of Mr. Thomas Simpson's notes at the end of the second edition of his Elements of Geometry.

"Art. 1. In page 257 and the next there is a long note, one design of which is to show the impropriety of conceiving one figure to be transferred from one place to another when the thing in hand can be done another way; he says Euclid has never recourse to this in other cases; but Euclid not only uses it in the 4 Prop. 1 and in the 24 Prop. 3. but also in the 4 Prop. 6. where he might instead of conceiving one of the triangles contiguous to the other with its base in the same straight line with the base of the other, have constructed a triangle in that position, having its sides equal, each to each, to the sides of the other; and in like manner the corollary of 1 Prop. 6 might have been shewn; but it would have been quite needless in either case. Mr. Simpson himself uses this method in the axiom before his $7^{\text {th }}$ Book, where without the least necessity he conceives the figure $P Q R$ to be formed equal and similar to the bases $A B C$, DEF and the prisms upon these last bases to be placed upon the base PQR; whereas he needed only have conceived the prism on the base $A B C$ to be applied to the prism on the base DEF so as their bases may coincide; but he has been afraid that they could not stand both together upon one base, and therefore he bids place them successively upon the base PQR."

The reader will remark the quaint humour of the close of this article: but long experience convinces me that very few pupils are able to abstract all notions of impenetrability when considering the geometry of solids. "The term "solid" is indeed an unfortunate one to have chosen, by which to designate a figure of three dinensions; and it is difficult to remove from the young mind some vague notion of the impossibility (or absurdity of directing it) of applying one solid to another so that both shall be in the same place at the same time. The method of Simson's Euclid is unquestionably legitimate: but something must be conceded in the outset of a new course of study to the youthful incapacity for abstraction. The conception of both solids being successively fitted into the same matrix, or in the form that Simpson gives it, is less likely to violate previous notions, than the more abstract and certainly more philosophical process. Neither is it inaccurate under any aspect as a method of reasoning; and the more desirable view will easily present itself to the mind of the careful student at a stage of reading not very remote.

But is the supraposition of a plane figure upon another $2 \mathrm{~K} 2$ 
plane figure materially different from this? For one line to be on another is surely not "coincidence" in the strict sense of the word; and certainly there is little reason to consider an argument founded upon two lines so situated, as a legitimate proof. Yet how few who have read Euclid have any other idea of supraposition! Euclid does not use the term; and no commentator or teacher who does use it, would pass it by without showing in what sense it is used. This is easily done by recalling the definitions of the point, the line and the plane, to the student's mind. The difficulty of perfect abstraction of some material properties is of the same nature here as in the case of "solids;" but it is much simpler, and more easily removed from the young mind.

As regards the legitimacy of the processes of transferring figures, so much has been said on both sides that it might be difficult to propound a view which somebody or other has not taken before. One thing, however, is clear; that no geometer has been successful in attempting to build up a legitimate system without the aid of this conception-either openly or in disguise. We are forced back, then, upon the necessity of using it; and perhaps our notions of legitimacy may be of too exalted a character to be ever realised. Are we sure, indeed, that our conceptions of form and the other properties of figure are not so obtained by us initially as to necessarily involve the consideration of transfer? Many considerations are involved in this question which lie beyond the ordinary range of geometrical discussion. It was evidently Euclid's desideratum to evade it; and yet he was unable to do so in $i$. 4, i. 7, and $i i i .24$ : nor has any one else succeeded in doing so with perfect strictness.

That this method of transferring figures was amongst the very earliest modes of demonstration, there can be no room to doubt; and that it was much more used (even in the school of Plato) before the time of Euclid, appears to me extremely probable. Little, perhaps nothing, is likely to be found of a documentary character either to bear out this view or to sweep it away. It is a natural mode of proceeding, and it is in a few cases even yet an inevirable one. The refinements introduced into geometrical reasoning by Euclid, or perhaps partially so before his time, induced the attempt to eliminate all idea of motion, as one of the properties of matter. It is on the same ground that corresponding modern refinements have been attempted, in which the principle should be completely carried out. That the conditions which determined the equality of two triangles were not determined originally without the adoption of the principle of transfer is almost certain; and as to many pro- 
perties of the circle in the third book, the two circles being left (both in the enunciation and demonstration), can only be accounted for on the hypothesis that the proofs we now have were modified from proof's by transfer. This (as well as the fact that most of them would be more neatly exhibited in reference to a single circle than to two) would seem to point out the change as an immediately recent one-most probably Euclid's own change. I cannot, however, further enlarge here upon this question.

“2. P. 261. The reasoning here is such that it is difficult to know what his meaning is. 'he says the question here, is, whether a triangle, under certain specified conditions, can, or cannot be formed? and therefor [e] to conclude any thing from the properties of Triangles would be ridiculous, and nothing less than begging the question.' does he mean that because the triangle is to be made, and not yet formed that therefore it is not allowable to conclude anything from the properties of triangles which have been already demonstrated? Were this true, he would, indeed, be in the right to affirm as he does that the problem has a limitation, yet it would be absurd to urge it in this case: he makes use of his own limitation in this Problem, and why may not Euclid make use of his which is easier to be understood, and the consequence from it that the circles will meet sufficiently plain. But really this deserves no serious reply."

That the conclusion of the intersection of the circles can be obtained from Euclid's limitation (viz. that any two sides of a triangle are greater than the third), is true enough : but that it is actually made to follow by any reason beyond "inspection" no one surely will say. A process tantamount to Simpson's is essential; and whilst many may think that the objection does "deserve a serious reply," no one will, I think, consider what is given above as any reply at all.

“ 3 . In the same note he observes that the point $F$ ought to have been shown to fall below the line EG (or rather, because the point $G$ is found by construction, that the point $G$ falls above EF.) this probably Euclid omitted, as it is easy to see that DF being greater than $\mathrm{DE}$ the angle DFE is less than a right angle, and producing $\mathrm{EF}$ to $\mathrm{H}$ that therefore DFH is an obtuse angle,

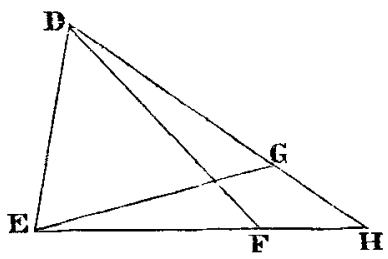
and consequently any straight line $\mathrm{DH}$ drawn to EF produced must be greater than $\mathrm{DE}$, and that $\mathrm{DG}$ which is equal to it must fall above EH."

That Simpson's objection was a valid one is now unques- 
tioned: whether the present completion of it, or that given in the note upon $i .24$ be satisfactory or not, will give rise to different opinions. It will be necessary to prove what Dr. Simson assumes in the opening of the above reply, that DFE is less than a right angle; and as to that in the note in Euclid, there is an assumption not at all warranted by anything prior to $i$. 24:-except, indeed, the warranty of his own precedent in $i .13$.

Simpson administers a very proper and dignified rebuke to the Doctor in the same note, but which is not noticed either in this MS. or in print.

" Professor Simson (at p. 359 of his Euclid, sto edit. 1756) has been a little severe upon me, on this head, for attempting to supply, what I thought a small defect in Euclid. "Who is so dull (says he) tho' only beginning to learn the Elements, as not to perceive that the circle described from the centre F \&c.' It is not without a real concern that I here see this able Geometer drop his own character so far as to express himself in a manner so very ungeometrical. If the thing is indeed so easy to be perceived, it must be so either as an object of the senses, that is, in plain terms, by inspection; or else it must be in consequence of geometrical reasonings antecedent to the thing itself. Now I am clear that he would not be thought to mean the former; and as to the latter nothing had been given from which the evidence of the inference could be so clearly seen : For though, \&c."

It may be added, that a particular object induced me a little time ago to note the assumptions that are tacitly made in the first book of Euclid. Whoever does the same will not be a little surprised at their number.

There is no doubt that Simson removed a great number of small blemishes from Euclid's Elements; but, it is equally certain, that he has still left a great many more than he has removed. He found some of them too firmly rooted into the system to be able to eradicate them without venturing upon far greater changes than he has done-and he showed no "lack of courage" in that way, either. The present is one of them; for the proof ought to form part of the text; whereas it is treated in a note as a thing "easy to see." The same assumption in a still more objectionable connexion occurs in the construction of $i .13$. For there it is assumed that the circle whose centre is $C$, and which passes through a point $D$ on the other side of the line $\mathrm{AB}$, will cut that line in troo points, $\mathbf{F}$ and $\mathbf{G}$; as otherwise the construction following could not be performed. It is also to be presumed that the circle can only cut the line in those two points; as if it cut in more than 
two, say $n$, then there could be $\frac{n(n-1)}{2}$ perpendiculars drawn from $\mathrm{C}$ to AB. The line FG must then fall wholly within the circle; whereas when we come to the third book we are required to prove this very property; and nore strangely still, to draw a straight line within the circle in the antecedent proposition. The difficulty is inherent in the method pursued. It compels the eye to supply the place of reason. We merely see that it is:-not know rohy it must be so. It is not by such phrases as "who is so dull as not to see?" or "it is easy to see," that this blemish can be removed.

I believe that no one who has been much concerned in mathematical education will complain of students "only beginning the Elements" being very short-sighted upon such points as these. They find it "easy to see" that many things are so and so which the tutor would prefer their proving. In these cases, it is not the fact that is in question, but its place in the logical system. Geometry by inspection is always more acceptable to the majority of young students than geometry by demonstrition. Mr. Byrne must have known this, when he carried the system to perfection in his Euclid in Colours. Did geometry, however, stop at visible properties, it would be jejune enough. I have often found, too, that the notion of the ultinate objects of geometrical research being principally graphic, or in some other way merely practical, has, whilst it has fostered the propensity to proof by inspection, generally led to much confusion in the student's mind. Let it always be presented to his mind as a rational science-never as a practical art, except, indeed, incidentally.

“4. In the same place he blames the bidding 'draw a straight line within a circle, without specifying that it must terminate in the circumference ' not knowing that this way of speaking is constantly used by Euclid and other Geometers; as not only in this $1^{\text {st }}$. of the $3^{\text {d }}$ but in the $4,14,15,28$ of the same book, and though the 2 Prop. of the $3^{\mathrm{d}}$ is to prove that a straight line joining any two points of the circumference is within the circle, yet surely there is no need of demonstrating that a straight line may be drawn somewhere within the circle; the $2^{d}$ Prop. being to shew that though the points be taken never so near to one another, that the straight line joining them will neither fall upon nor without the circumference."

Simpson had only noticed this as an instance of vague expression. Is it not such? Is it not more-even much more?

“ 5 . In the same note he answers what is said in page 415 . of the $4^{\text {to }}$ English Edition, that it ought to be demonstrated not assumed that a straight line cannot meet a straight line in more than one point, and says it cannot be demonstrated, and that the Editor refers 


\section{Mr. T. S. Davies on Geometry and Geometers.}

it to the $14^{\text {th }}$ axiom of Book 1. (he means in Barrow's Euclid, for it is the $10^{\text {th }}$ in the Greek). but all that in this case follows from that axiom is that if two straight lines $A B, C D$ cuuld meet with each other in two points $E, F$, the parts of them betwen $\mathrm{E} \mathrm{F}$ must coincide, and so $A B, C D$ would have the segment common to both; but this does not prove that they cannot meet in two points, from which their not having a common seg-

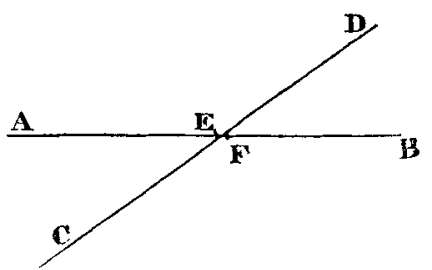
ment is deduced in the Greek Edition. but because they cannot have a common segment, as is shewn in Cor. of 11 Prop. $1.4^{\text {to }}$ Edition it follows they cannot meet in two points."

As regards a logical system, Dr. Simson is right in this view; but in all that relates to the line and plane, especially the first steps of deduction, there exists in most minds some degree of confusion, arising from the vagueness of the definitions of those objects of our contemplation. In discussing Euclid's method, it appears to be almost always forgotten that his metaphysical creed was Platonism; and questions arising out of such antecedent creeds always must present themselves in the initial steps of a science.

It cannot be denied that Simpson might have retorted, had he seen this, "who is so dull as not to perceive that two straight lines cannot meet in two points?" It would be an assumption far less removed from our first conceptions than some that Euclid makes and Simson justifies.

"6. P. 265. The observation at the end of the note which begins in p. 264, viz : that in the Corollary (of Prop 11 Book 1.) the lines A B, B D, B C are supposed to be all in the same plane, which cannot be assumed in 1 Prop. 11 . is very just. Soon after the $4^{\text {to }}$ Edition was published I observed this error and corrected it in the way Mr. Simpson has mentioned in this note. he is mistaken in thinking the $10^{\text {th }}$ axiom he mentions here, to be Euclid's, the Axiom he means is That two straight lines cannot have a common segment, which is none of Euclid's, but is the 10 $0^{\text {th }}$. in Dr. Barrow's Edition, who took it from Herigon's Cursus vol. 1. and to supply this, is the design of Corollary 11 Prop. 1.

“7 7. Page 267. and the following contain several objections against Euclid's doctrine of Proportionals, most of which with many others, have been long ago distinctly and fully answered by the learned Dr. Barrow in the $7^{\text {th }}$ and $8^{\text {th }}$ of his Mathematical Lectures. Some of which relate to the notes on the $4^{\text {to }}$ Euclid are as follows.

“ 8. At the bottom of P. 270 he says that 'Euclid or Eudoxus does never (that I know of) refer to any definition till he has proved either by actual construction, or by some Demonstration previous to that in hand, that such definition involves no absurdity \&c.' the 
contrary of this is manifest, for instance in the $4^{\text {th }}$ Prop. 5 he refers to (or makes use of ) 5 Def. 5 without ever having mentioned it, or proved anything about it, after he had given it. $\mathrm{D}^{\mathrm{r}}$. Barrow has sufficiently shewn the weakness of such objections; see his Lect. Mathem : P. 299 near the end, and the sentence which begins in the last line of Page 303. nam si \&c."

Dr. Simson must have been "hard driven" for an objection to Simpson, to have quoted this case: inasmuch as it so far furnishes a new argument against the perfection of Euclid's work; and thereby affixes a stigma to the "4to Edition," which is as yet unremoved from any subsequent one. That the canon enforced by Simpson is a safe, a sound, and an essential one, who will deny? Nay, more:- not only should the consistency of the definition be shown, but its completeness, and its freedom from redundancy, likewise. There is perhaps no instance in Euclid of incompleteness of defining conditions: but there are several of redundancy-such as the square, and similar rectilineal figures, so often quoted by editors and commentators. The mischief done in such cases as these is rather done to the logic than to the geometrical facts: but then, on the other hand, these superfluous conditions might be contradictory to the essential ones, just as easily as consistent with them, or consequential from them.

Instead of collecting all the definitions at the beginning of a book or treatise, many judicious writers prefer to give them pari pussu, as the occasion for them, as well as their justification, shall present itself. Probably the fifth definition of the fifth book and those connected essentially with it, may present a good argument in favour of such a mode. In more elaborate researches, and especially in the theories of modern geometry, this becomes almost indispensable; as for instance in the doctrine of "radical axes," "similitude," "poles and polars," "anharmonic ratios" and "involution." Many points, lines, circles, ratios, and relations of different kinds here demand specific names, which till their necessary existence has been proved, it would be a manifest absurdity to confer upon them. Under all circumstances, at any rate, whatever arrangement may be given to the definitions in a printed book, it is essential to observe the canon enforced by Simpson, as above quoted, in giving the composition and logical place of every definition.

It would require more space than I have at my disposal to enter upon the question of Euclid's fifth definition of his fifth book; and as I cannot treat it adequately, it must be passed over altogether, till some future time. For the same reason, I shall here offer no remark upon the portions of this paper of Simson's, which bear upon the fifth book. 
Yet whilst I avoid such extended discussions as I should be entangled in by this subject, it is certainly due to Thomas Simpson to state, that all geometers have not entertained, and do not now entertain, that high estimate of Dr. Barrow's treatment of ratio that Dr. Simson did, and which he here so triumphantly quotes. It is satisfactory to be able to state my own view in the felicitous language of a dispassionate judge, and of one whose philosophical acumen in such matters needs no praise of mine, Professor Powell. In a paper read before the Ashmolean Society of Oxford in 1836, he thus expresses himself:-" Dr. Barrow, in his celebrated Mathematical Lectures for 1666, has treated the whole subject of ratios and proportion in the most copious and elaborate manner, but, as appears to me, with more learning than perspicuity; he is extensively occupied in examining and refuting such objections as those just adverted to; and in doing so seems more explicit and satisfactory, than in any attempts to elucidate directly the doctrine itself on real philosophical principles. In point of fact, in the midst of his very extensive dissertations, it is far from an easy matter to discover what is his own idea of the nature of ratios; and when it is developed, it is by no means clear wherein it substantially differs from the views of some of his opponents" (p. 14). I not only fully concur in this view, but 1 believe that much of the praise bestowed upon Dr. Barrow's Lectures on this subject, has been bestowed for fashion's sake, and not from those writers having read and unravelled that complicated series of discussions.

“ 9. In P. 379 of the $4^{\text {to }}$ English Edition it is said That in order to prove what is affirmed in the Demonstration of 10. Prop. 5 in the Greek Edition viz : that A cannot have a less ratio to $C$ than $B$ has to it, it ought to have been shewn that if the ratio of $A$ to $C$ be greater than that of $B$ to $C$. and taking any equimultiples of $A$ and $B$, and any multiple of $C$., the multiple of $A$ is ever greater than that of $C$ whenever the multiple of $B$ is greater than that of $C$; but this is not done in the 10 Prop. but would easily follow from it and cannot without it be easily demonstrated. The author of the notes on the $8^{\text {vo }}\left[4^{\text {to }}\right.$ ? the 8 vo was not published till after Simpson's death] Edition sayes, that this point ought to have been cleared up by propositions antecedent thereto and independent thereupon (I suppose he means upon the $10^{\text {th }}$. Proposition, else I do not understand him) and adds that the $8^{\text {th }}$ Prop. seems the proper place for doing it. then he gives an account of what is proved in Prop. 8 . and next gives a demonstration that the ratio of $A$ to $C$ cannot be less than the ratio of $B$ to $C$. but in the very first words of it, he supposes that $A$ is greater than $B$, which is the thing that is proved in the $10^{\text {th }}$ Prop. and therefore he has done it by the help of the $10^{\text {th }}$, tho, a little before, he had said it should be done by propositions independent upon it; his demonstration is exactly the same with that at the 
end the notes on the 10. Prop. Page 380 of the English $4^{\text {to }}$ Edition which he says ought to have preceded the $10^{\text {th }}$. it can, it is true, be done without the $10^{\text {th }}$ but not so easily.

"10. In P. 271. at the bottom, he sayes "the same oljection oc' curs again in the $13^{\text {th }}$ Prop. where it remains in its full force, for - though it be allowed that there are some equimultiples of $\mathrm{C}$ and $\mathrm{E}$ ' and some of $\mathrm{D}$ and $\mathrm{F}$ such, that the multiple of $\mathrm{C}$ is greater than ' the multiple of $\mathrm{D}$ but the multiple of $\mathrm{E}$ not greater than the multiple - of F ; yet it is not demonstrated nor in any sort shewn, that other - multiples of these quantities cannot be taken such that the very con' trary shall happen.' No indeed, for the very contrary may often happen; but this has not the least force against the demonstration Euclid gives of the $13^{\text {th }}$ Prop. for since it is allowed, that such equimultiples can be taken as just now mentioned, the Demonstration of the $13^{\text {th }}$ remains firm and legitimate, but indeed what he sayes here is so far from having the least appearance of an objecrion, that the mildest thing [that] can be said of it is, that the author has been in so great a hurry as not to have taken time to consider what he was writing.

"11. In P. 272. at the foot, he mentions the principle whereby the difficulty he had before spoken of might be obviated, viz: " that if a - magnitude of any kind be given, or propounded, there may (or can) - be another magnitude of the same kind which shall have to it any ' ratio assigned,' or which is the same thing, that unto any three magnitudes two of which are of the same kind, there can be found a fourth proportional. This he sayes I will by no means admit of (tho Euclid himself in 2. Prop. 12. has used it) and in P. 70 of his Elements at the foot he had said that 'this kind of argumentation ' is authorised and adopted by Euclid himself in his twelfth book' as to which is to be observed that Euclid in the 12 Prop. 6 has shewn that a fourth proportional can be found to any three straight lines, from which what he assumes in the 2 Prop. 12 can be legitimately deduced, as is shewn in the note at the foot of the page in the $4^{\text {to }}$ Edition [and in all subsequent ones the same note is retained] at that proposition. but his using here will not infer that he would have used it betore he had shewn the 12. Prop. 6 .

" 12. Near the end of P. 274 the author is for "entirely rejecting 'the $10^{\text {th }}$ and $13^{\text {th }}$ Propp. of Book $5^{\text {th }}$ and everything else founded on ' the Definition of a greater and less ratio, as being of no other use in ' the Elements than to open the way to these important theorems on 'the alternation and equality of ratios' (by the last he means the 22 Prop. 5.) ' which may be better demonstrated without them, from the 'Definition of equal ratios alone, \&c.' but tho the $14^{\text {th }}$ and $20^{\text {th }}$ Propp. 5 on which the 16.22. depend, can be shewn without the help of the $10^{\text {th }}$ and $13^{\text {th }}$ yet since these two last are frequently used both by antient and modern geometers, they ought to have a place in the Elements; and since they are there, it was proper to demonstrate the $14^{\text {th }}$ and $20^{\text {th }}$ by them as it is done without any construction by taking equimultiples.

" 13. As to what is said concerning a nature or idea (' see P. 273' 
in margin) antecedent to that given in the $6^{\text {th }}$ and $8^{\text {th }}$ (he means the $5^{\text {th }}$ and $7^{\text {th }}$ in the Greek Text) Definitions of the $5^{\text {th }}$ book, $D^{r}$. Barrow has so fully answered it that nothing further need be added.

"14. Tho Mr. Thomas Simpson is a very able Mathematician, yet he is very much displeased at the high encomiums and extravagant commendations that have been lavished on this $5^{\text {th }}$ book of Euclids; and adds that 'this superb fabrick of proportions, reared ' with so much art, stands upon a tottering foundation' but $D^{r}$. Barrow who gives it the highest Encomiums, and who is the person, I believe, he chiefly intends here, was, as is well known, an exceeding modest man, and never launched out too far in behalf of opinions he had adopted; he was on every account, one of the best judges of this affair, and with respect to such objections as have been here taken notice of against Euclid's Definition sayes in Page 297 of his Lect : Mathem : that this definition 'nisi machinis impulsa validori 'bus in æternum persistet inconcussa."

I have not observed in Simson's correspondence with Nourse, any allusion to this paper. It does not, indeed, follow that because no chasm appears in the letters of this period between them, by reference to missing ones in subsequent letters, that all the letters which Simson wrote to Nourse (the one, specified formerly, excepted) are preserved. It is not unlikely that this paper was written soon after Simson's receipt of Simpson's book; as much to satisfy Nourse with his purchase of Simson's copyright as anything else*. One or two passages of the ad captandum kind would seem to bespeak such a purpose. Why else the sneer about the able "mathematician" at the opening of art. 14, as a preliminary to his being so strongly contrasted with Dr. Barrow for modesty and learning? The character of the paper is, on the whole, marked by a hauteur towards Simpson, that is only excusable in the writer, from a consideration of his age and the profound respect with which he had so long been treated by his own

* It is a remarkable circumstance, that whilst Simson's Euclid is the universally-adopted text-book in geometry in England, it is almost as uniyersally discarded in the Scottish schools and colleges-even in Glasgow itself. In Ireland, Elrington's edition is used; and on the Continent, the Elements is only viewed as a work of learned curiosity, and quoted, where quoted at all, for the purpose of animadversion. The honour of a prophet in his own country is here verified indeed! I have often thought, whilst reflecting upon this, that the maintenance of the preference for Simson's edition in this country was due to the earnest manner in which its superiority was urged at Cambridge by Dr. Robert Smith, and the respect paid to Nourse's known good judgement at Oxford. Probably, but for this, Thomas Simpson's Elements (the best, perhaps, we yet possess, which does not follow close in the wake of Euclid) might have now held the same position in this country that Legendre's does in France; at least if our national propensities to admire everytling antique should not have given rise to some new translation with its distinguishing variations. 
little circle in Glasgow. Simson was there, what Johnson was in his "Club" in Fleet Street.

Simpson is the only author referred to by Simson, who was both British and unadorned by academic titles; and be is introduced into the first and second editions of the Euclid almost by inevitable necessity. Throughout, he is rather a social parvenu than a scientific brother. In many of the views of the preceding paper I concur: still I cannot but regret the tone in which some of them are expressed. The mode, too, in which Dr. Trail refers to Simpson is in too strict keeping with a feeling of contempt towards "those whose works had been criticised in the Doctor's notes;" the reference applying, as far as $I$ have been able to ascertain, to Thomas Simpson only. No other author of the time is mentioned, or even alluded to, in Simson's Notes, and indeed no other work on the Elements of Geometry was published during the interval in question. 'The first edition of Emerson's was in 1763, and I find no allusion there to Simson or to Simpson either.

I have more particularly alluded to the matters in the preceding paragraph for the purpose of remarking that if a mathematician of Simpson's eminence (and I may add of Simpson's European reputation too) could be thus sifflé by "titled scholars," we cannot wonder at the general neglect with which the host of geometers in humble life, during the last century and first quarter of the present one, have been treated by academic bodies*. Few of my readers have the least idea of the existence of a body of men who, through several successive ages, have cultivated geometry with an ardour that is probably unexampled, and with a degree of success commensurate with that ardour. 'Their reward, as well as their patrimony, was poverty; and their fame was limited to their own narrow circle.

- As a specimen of even a somewhat recent manifestation of this spirit, 1 may quote Dr. Cresswell's treatise on Maxima and Minima. He says, "the Elements of Thomas Simpson contain a series of propositions on the Maxima and Minima of Geometrical Quantities, in which there is not much that is original" (p. 5). I confess myself unable to find in any writer antecedent to Simpson, a large relative portion of the propositions in his book, and I cannot accede to the dictum of Dr. Cresswell, except in the qualified sense of the chapter itself being a 'little' one-barely fifteen pages. But when a writer thus becomes critical upon the subject of originality in others, we have a right to test him by the same criterion. What is there " new" in Dr. Cresswell's own treatise, either as to principle, method of development, or final result? Certainly a finer opportunity for the production of a truly classical work on the subject was never thrown away by any writer. Cresswell's volume on this one subject is really larger than Simpson's entire treatise on geometry generally. No man can do much in fifteen pages, but any competent person might do a good deal in 273 . 
Their works, however, live after them : but at present, chiefly forming portions of books of high pretensions, and bearing other names than theirs on the title-pages. These were men of the school of Thomas Simpson; their career was marked out by him; and their tastes were formed upon the models which he bequeathed to them. It may be safely affirmed that, as regards geometry generally, and geometrical construction especially, no works in our language furnish so many beautiful, varied, and instructive exemplars as the three works of Simpson, viz. his "Elements of Geometry," the supplementary part of his "Elements of Algebra," and the second part of his "Select Exercises." It is much to be regretted that Dr. Stewart's Propositiones Geometricce was not added to the scanty libraries of these able geometers, by its being published in their own, instead of a dead language. 'That day of learned foppery is, however, gone by, when a man who wishes to publish a work on science must claim his title to "respectable birth, parentage, and education," by his Latin prose composition, before he can obtain the notice of the dilettanti of the so-called literary and scientific world. Justice, however, will yet be done to these men, humble artisans, excisemen, and country-schoolmasters though most of them were. The able analyses of their little duodecimo annuals which is in progress in the Mechanics' Magazine, by Mr. Wilkinson of Burnley, will do much towards effecting this purpose; and I should hope that book-manufacturers will in the end be compelled to bow to the force of public opinion, so far as to give at least some distinct acknowledgement of the sources whence they obtain the materials of their works. A work might be pointed out-a work which has passed through several large editions, and produced to its "author" large sums of moneywhich is made up wholly out of the periodicals written by these men-without, in any single case, more than a verbal alteration in the solutions, and very rarely even so much as that. Yet there is not the least hint given as to whence these beautiful investigations were taken; nor indeed any marked indication that they did not "drop from the clouds," or were the honest produce of the mind of him whose name adorns the title-page.

Shooters' Hill, Oct. 27, 1849. 